\title{
Theoretical and Methodological Background to Environmental Training of Students of Technosphere and Fire Safety Profile
}

\author{
Vinogradov O.S. \\ Department of Protection in Emergency Situations \\ K.G. Razumovsky Moscow State University of technologies and \\ management (the First Cossack University) \\ Moscow, Russian Federation \\ e-mail fox-bbs@mail.ru
}

Zaitsev V.Yu.

Department of Protection in Emergency Situations

K.G. Razumovsky Moscow State University of technologies and management (the First Cossack University)

Moscow, Russian Federation

e-mail vluzai@gmail.com

\section{Koroleva T.I.}

Department of Fire Safety

K.G. Razumovsky Moscow State University of technologies and management (the First Cossack University)

Moscow, Russian Federation

e-mail korolevatamara@mail.ru

\author{
Vetlugina G.P. \\ Department of Protection in Emergency Situations \\ K.G. Razumovsky Moscow State University of technologies and \\ management (the First Cossack University) \\ Moscow, Russian Federation \\ e-mailgalavet@lenta.ru
}

Kaleda I.A.

Department of Fire Safety

K.G. Razumovsky Moscow State University of technologies and management (the First Cossack University)

Moscow, Russian Federation

e-mail kaleda-gts@yandex.ru

Bochkareva L.P.

Department of Protection in Emergency Situations

K.G. Razumovsky Moscow State University of technologies and management (the First Cossack University)

Moscow, Russian Federation

e-mailmila58reg@yandex.ru

Many works of practicing psychologists and teachers conclude that the students' research projects using IT technologies contribute to students' satisfaction with the quality of education [3]. The use of computer programs in the study of basic and principal disciplines is a priority these days, especially during laboratory classes at higher educational institutions. Now almost all disciplines are somehow connected with IT technologies. [4, 5, 6]. However, ecological education, similar to any other, is impossible without the use of modern technologies [7]. At the same time, it is believed that modern students are characterized by the domineering visual channel of obtaining the information. It shall clearly be stated here that the training of highly-qualified specialists, i.e. competitive on the labor market, is only possible if digital technologies are utilized [8].

Thus, in the majority of cases the modern level of ecological education of university graduates requires modernization, knowledge focus and the maximum use of IT technologies.

\section{PURPose OF THE STUdY}

To define opportunities for quality improvement of ecological education at higher educational institutions. To develop methodical recommendations for curricula design within Technosphere Safety and Fire Safety profiles in order to foster the corresponding outlook and ability to sum up the entire 
situation in the assigned facility from environmental perspective.

The study was conducted using standard methods to assess the level of knowledge acquisition within educational disciplines, external testing of students via the uniform portal of Internet testing in education. The assessment of the quality of graduates within a quality management system was based on the annual survey of employers, which results formed the basis for recommendations on quality improvement in ecological education.

\section{RESULTS}

The monitoring of the level of education covered students of Technosphere Safety profile (Protection in Emergency Situations) and Fire Safety profile (Fire Inspection). At the first year the students study Ecology, which is fundamental for further study of ecological disciplines. Such disciplines include Industrial Ecology, Eco-Protective Equipment and Technologies, Physical and Chemical Processes in Technosphere, Natural Hazards. Besides, there are disciplines that cover ecological topics in separate blocks (modules). They include Medical and Biological Fundamentals of Life Safety, Modeling of Emergency Situations.

Let us consider the interaction between disciplines taking into account the educational specifics. The discipline Ecology provides key terms, concepts and definitions for all main sections, starting from the history of ecology as a science to global problems of the humankind. Fundamentals of bioecology, geoecology, industrial ecology, etc. are studied here. Then, after the study of Chemistry and Physics within the profile subject Physical and Chemical Processes in Technosphere such phenomena as smog, acid rains, erosive processes, chemical activity of pesticides in soils etc. are considered. In other words, students get deeper knowledge on physical and chemical mechanisms causing changes in the environment. The discipline covers numerous real case studies. In practice, students collect and analyze contaminated soil samples taken from fields, from industrial areas of large enterprises, study the quality of polluted air collected near the highway, etc. The profound laboratory work within the discipline also contributes to the development of students' knowledge and skills - students perfectly know the main pollutants and ways of their migration in the environment.

The next discipline is Industrial Ecology, which fosters the development of knowledge gained through the previous course, with the introduction of computer processing of data with elements of process modeling. This discipline covers the basic understanding of methods related to sewage treatment, emissions, and general waste treatment. Let us consider how computer programs are applied in Industrial Ecology. The software packages are aimed for stage-by-stage learning within the discipline. Thus, the first practical task in the study of topics related to anthropogenic environmental pollution is the calculation of the amount of water for sewage dilution from an industrial facility. Here for the first time the students face such phenomena as water classification, make two calculation options for fishery, household and drinking reservoirs. The calculation is made against various chemical elements contained in the drainage systems. Next, the students study more complex sewage treatment systems, estimate options satisfying the requirements of water discharge regarding maximum-permissible concentration, choose certain filtering elements, etc. The final practical task is the choice of the water treatment system for the enterprise with further calculation of its efficiency and economic profitability.

Electrochemical production exerts the highest impact on water pollution in the midland of Russia in terms of heavymetal ions, hence, students learn about relevant methods used to create the closed-circuit electroplating industry. The main stage of production leading to the most intense discharge is the workpiece washing $[9,10]$. The software package allows selecting not only a certain type of flushing operation, but also designing a closed drainage system within a given processing line (Fig. 1). This practical task is always preceded by a visit to any electrochemical plant thus giving students the opportunity to see the real problems. 
Calculation of water consumption for flushing for different flushing schemes

About

Calculation of water consumption for flushing for different flushing schemes

Enter the following values

$$
\begin{aligned}
& C_{0}=125 \mathrm{~g} / \\
& q=0.21 / m^{2} \\
& \mathrm{C}_{\mathrm{n}}=0.01 \\
& F=0.7 \quad \mathrm{~m}^{2} / \mathrm{h}
\end{aligned}
$$

\begin{tabular}{|c|c|c|c|c|c|}
\hline$T \cdot W$ & 1750 & $\mathrm{~T} \cdot \mathrm{Tr} \cdot \mathrm{W}$ & 700 & $\mathrm{~T} \cdot \mathrm{Tr} \cdot \mathrm{Tr}-\mathrm{W}$ & 263 \\
\hline$T \cdot W \cdot W$ & 32 & $T \cdot T r-W \cdot W$ & 20 & $\mathrm{~T} \cdot \mathrm{Tr} \cdot \mathrm{Tr} \cdot \mathrm{W} \cdot \mathrm{W}$ & 13 \\
\hline$T \cdot W \cdot W \cdot W$ & 10 & $\mathrm{~T} \cdot \mathrm{Tr} \cdot \mathrm{W} \cdot \mathrm{W} \cdot \mathrm{W}$ & 8 & $\mathrm{~T} \cdot \mathrm{Tr}-\mathrm{Tr}-2 \mathrm{CW}$ & 7 \\
\hline $\mathrm{T} \cdot 2 \mathrm{CW}$ & 16 & $\mathrm{~T} \cdot \mathrm{Tr} \cdot 2 \mathrm{CW}$ & 10 & $\mathrm{~T} \cdot \mathrm{Tr}-\mathrm{Tr}-3 \mathrm{CW}$ & 2 \\
\hline $\mathrm{T} \cdot \mathrm{W} \cdot 2 \mathrm{CW}$ & 7 & $\mathrm{~T} \cdot \mathrm{Tr} \cdot \mathrm{W} \cdot 2 \mathrm{CW}$ & 5 & $\mathrm{~T}-\mathrm{Tr}-\mathrm{Tr}-\mathrm{Tr} \cdot \mathrm{W}$ & 105 \\
\hline $\mathrm{T} \cdot 2 \mathrm{CW} \cdot \mathrm{W}$ & 7 & $\mathrm{~T} \cdot \mathrm{Tr} \cdot 2 \mathrm{CW} \cdot \mathrm{W}$ & 5 & $\mathrm{~T}-\mathrm{Tr}-\mathrm{Tr}-\mathrm{Tr}-\mathrm{W} \cdot \mathrm{W}$ & 8 \\
\hline $\mathrm{T}-3 \mathrm{CW}$ & 4 & $\mathrm{~T} \cdot \mathrm{Tr} \cdot 3 \mathrm{CW}$ & 3 & $\mathrm{~T}-\mathrm{Tr}-\mathrm{Tr}-\mathrm{Tr}-2 \mathrm{CW}$ & 4 \\
\hline
\end{tabular}

Scheme of washing water consumption, $1 / \mathrm{h}$ Scheme of washing water consumption, $\mathrm{l} / \mathrm{h}$ Scheme of washing water consumption, $\mathrm{l} / \mathrm{h}$

Fig. 1. Calculation of water consumption for flushing for different flushing schemes

A similar software package is used to calculate air emissions from industrial facilities. Besides, there is a laboratory research to study the level of pollution from motor transport. Students measure the level of pollution (in the morning, during rush hour and in the middle when the traffic is not heavy) near the highway (near the traffic light, at intersections, etc.), consider the quantity and type of cars moving per unit of time. Then, they estimate the level of environmental pollution and make relevant conclusions in the corresponding computer program.

The analysis of the students' knowledge of the material was held for 3 years among full-time students of different years of study. The results of the level test on Industrial Ecology and the bottom-line figures clearly demonstrate the efficiency of computer processing programs in combination with real research work. Students become more capable to make a comparative analysis regarding various water treatment systems, to draw certain conclusions on their rational use. Students easily acquire the information on the efficiency of water treatment facilities and their use in certain situations. Such result is achieved by multiple tests and modeling of certain production scenarios, which seems impossible without the relevant IT support.

Besides, all software programs for Industrial Ecology are designed in compliance with regulatory documentation for the calculation of emissions and discharges. The software allows editing the amount of current penalties and payments for standard discharge operations thus helping students that prepare their final qualification work to prove or disprove the efficiency of the operating facility. Students prepare their final qualification papers starting from the first year of study. For this purpose, the schedule implies the so-called "days of projectbased learning".

Upon the completion of the course on Industrial Ecology, students pass to the next stage and study the more complex technical discipline on Eco-Protective Equipment and Technologies. This course represents the combination of the well-known program Processes and Devices of Chemical Production with elements of environmental protection equipment. Here students get deeper understanding of equipment assembly, operating principle of the main types of equipment used for sewage water treatment and various air emissions, learn to make design calculations. During practical classes, the students plot the calculated devices (mandatory vacuum drum filter, cyclone, and other equipment - according to task options) in Compass environment. Students design process flow charts using the calculated equipment (only sample tasks), learn to modernize the existing process charts by the example of reagent sewage water treatment. Definitely, the 
specialists in the field of technosphere and fire safety are not designers, but the knowledge gained during this course gives them a fair opportunity to understand the treatment processes.

The next block of disciplines is aimed to study natural and technogenic processes most likely leading to emergency situations. Such disciplines include Natural Hazards and Modeling of Emergency Situations. The basic disciplines within this block include Ecology, Combustion and Explosion Theory and Fire and Explosion Protection. During the study of natural hazards, great attention is paid to the study of territorial features of the Russian Federation, its climatic conditions, potential threats, and the relevant emergency response system. Quite often, the practical classes are held at fire rescue stations. Then, students learn to forecast and simulate any emergency situation. For this purpose, students are given a certain natural problem with exact location data and then, using specialized programs, students make forecasts. Certainly, many industrial enterprises are potentially dangerous. However, during classes on Modeling of Emergency Situations these problems are not studied to the same extend as the natural disasters. It is caused by low availability of exact data (for obvious reasons) regarding specific conditions of a hazardous industrial facility. Modeling begins with standard calculation of the depth of infection (Figure 2) made in relation to an abstract object with particular emission (leakage) of chemically or radiation-hazardous materials (without being bound to any particular city or settlement). Then, the students model the situation using special programs taking into account wind speed and direction, temperature and humidity of air, etc. The situation is considered in an hour, two hours, a day, a week taking into account the remedial measures or without their consideration. Students make conclusions on damage to flora and fauna, as well as on any threat to the life and health of the population. Upon task completion, students try to propose specific measures to prevent emergency situations or measures to eliminate such situations in the shortest time possible.

At all stages of practical work students collaborate with firefighters and rescuers in dedicated sites where students master their knowledge and skills of rescue equipment and tactics, which is critical in the analysis of the shortest possible ways of eliminating the environmental emergency whatever is the cause.

Throughout the entire study, the students passed tests and took exams to check their residual knowledge taking into account various approaches to the implementation of educational programs. For instance, the students of the Technosphere Safety profile studied the disciplines in the order described above, and the practical classes considerably exceeded the lecture hours. Most of the practical classes covered field tests and use of IT resources. The students of the Fire Safety profile were trained according to the classical model where the number of lecture and practical (laboratory) classes was quite similar. Students of both profiles participated in all environmental events and actions initiated by the university. Students developed almost the same level of ecological mindset through meetings, conversations with experts, training sessions and seminars.

\section{DISCUSSION}

The main objective of education monitoring is to reveal the most productive and perspective teaching methods and approaches. The development of knowledge in the field of ecology is a crucial task, especially if it concerns specialists that are key in preventing dangers to the environment. The specialists of Technosphere Safety profile work not only in rescue and firefighting units, but also as safety and industrial ecology engineers, as well as fire safety engineers and inspectors similar to specialists of other profiles. It is no doubt that timely prevention of ecological dangers to the person and the environment depends on the level of their knowledge and responsibility. The analysis of graduates' competences of both profiles gave positive results, which is quite rewarding. However, there are some differences - students with bigger experience of practical work and field study easier get a job (employment ratio makes nearly 100\%). Students are not afraid of new positions and expansion of the sphere of their responsibility. There were cases of employment to a position related to labor protection and ecology with subsequent promotion to leadership positions. In general, the students understand technical aspects well and easily master the relevant software (after modeling and design they are not afraid of the user's software). In any case, the employers are satisfied with the graduates and their results. Besides, the University Alumni Association ensures continuous monitoring of graduates' performance. 


\begin{tabular}{l} 
About Language \\
Storage capacity \\
Name of substance \\
Wind speed \\
Time since the accident \\
Aggregate state \\
Air temperature \\
The degree of stability of the atmosphere inversion \\
The equivalent amount-1 \\
The equivalent amount-2 \\
The depth of the zone of infection the first cloud \\
The depth of the zone of infestation by the second cloud \\
Depth of infection \\
\hline 1 stage \\
\hline
\end{tabular}

Fig. 2. Software interface to calculate the depth of infection with chemically hazardous substances

\section{CONCLUSIONS}

The results of the study and the analysis allow concluding that the training of highly qualified specialists in the field of technosphere and fire safety requires the increase in the practical load as much as the educational standard allows. The increase in the amount of field tests and active use of modern IT during the study of ecological disciplines leads to quality improvement of knowledge and development of pro-active attitude towards environmental protection.

\section{References}

[1] N.V. Levchenko, "Shaping ecologically focused worldview in education: Theoretical approaches," Integration of Education, Vol. 20(3), pp. 364373, 2016. DOI: 10.15507/1991-9468.084.020.201603.364-373.

[2] I.V. Tsvetkova, T.N. Ivanova, "Social criteria of young people's environmental responsibility," Integration of Education, Vol. 21(4), pp. 723-735, 2017. DOI: $10.15507 / 1991-9468.089 .021 .201704 .723-735$

[3] W. Strielkowski, L.S. Kiseleva, E.N. Popova, "Factors determining the quality of university education: Students' views," Integration of Education, Vol. 22(2), pp. 220-236, 2018. DOI: 10.15507/19919468.091.022.201802.220-236.

[4] I.V. Akimova, M.A. Rodionov, N.N. Khramova, E.I. Titova, A.Y. Behter, O.M. Gubanova, P.G. Pichugina, "Studying the Elements of Fuzzy
Mathematics within Subject Training For Pedagogical Students of the Informatics Profile," International Journal of Humanities and Cultural Studies, pp. 262-270, 2016.

[5] M.A. Rodionov, I.V. Akimova, G.I. Shabanov, "Elements of fuzzy logic as a component of professional and pedagogical training of future mathematics and informatics teachers," Integration of Education, Vol. 21(2), pp. 286-302, 2017.

[6] E.V. Beresneva, M.A. Zaitsev, R.V. Selezenev, L.V. Darovskikh, M.M. Solomonovich, "Didactic potential of modern information technologies in training a chemistry graduaten," Integration of Education, Vol. 22 (1), pp. 177-192, 2018.

[7] E. Smyrnova-Trybulska, T. Noskova, T. Pavlova, O. Yakovleva, N. Morze, "New educational strategies in contemporary digital environment," International Journal of Continuing Engineering Education and Life-Long Learning, Vol. 26 (1), pp. 6-24, 2016.

[8] T.N. Noskova, T.B. Pavlova, O.V. Yakovleva, "Analysis of domestic and international approaches to the advanced educational practices in the electronic network environment," Integration of Education, Vol. 20 (4), pp. 456-467, 2016.

[9] O.S. Vinogradov, Yu.P. Perelygin, "Electrolytic deposition of the zinccobalt alloy," Russian Journal of Applied Chemistry, Vol. 74 (3), pp. 421 423, 2001.

[10] S.N. Vinogradov, G.N. Maltsev, N.A. Gulyaeva, "Electrodeposition of a palladium-copper alloy in nonstationary electrolysis," Russian Journal of Electrochemistry, Vol. 37(7), pp. 715-717, 2001. 